\title{
Research and Implementation of College Students Scholarship Evaluation System
}

\author{
Ting Ding ${ }^{1,}$, Xinhao $\mathrm{Ji}^{1,2, \mathrm{~b}}$ \\ 'Zhejiang Business College, Hangzhou 310053, China; \\ ${ }^{2}$ East China Normal University, Shanghai 210062, China. \\ adt@zjbc.edu.cn, bjxh@zjbc.edu.cn
}

\begin{abstract}
After college enrollment, source structure became more complex. In daily work, scholarship students management review covering all aspects of the system to achieve can effectively improve the quality of management, and managers at all levels to facilitate students in real-time to understand and master the latest information and analysis of the students, the establishment of efficient work management system, developed in line with the actual demand is particularly important.
\end{abstract}

Keywords: scholarship; evaluation; research.

\section{Introduction}

In recent years, the increasing scale of running universities, the trends of diversified enrollment and the more complex student source structure their daily work makes it increasingly difficult to extract valuable information from huge data volume and also directly affects the accuracy of information collection for student mangers. In order to improve the efficiency of student managers, it has turned into urgent requirements to facilitate real-time understanding, grasping and analyzing the latest information of students, to establish efficient management systems and to develop scholarship systems which meets the actual demand of students.

\section{Background and Predicament}

With the growing expansion of colleges and universities, student source structure became more complex and students' management is faced with new challenges, the specific performance is as follows:

\subsection{Despite of increasing enrollment, students work is still using the traditional manual} management or simple office automation tools.

Increasing college enrollment result in growing numbers of students, management work needs to consume more resources by traditional manual management or simple office tools which makes it hard for student managers to grasp the dynamic information of students and takes a lot of time and effort to extract the large amounts of data volume.

2.2 The new student status system and the academic score system variation rise the difficulty of student management work.

In order to meet the cultivation of complex college personnel requirements, the university implemented a credit management mode which is more human-based to promote all-round development of the students, but is not conducive to master the students' basic information as fast as possible. Besides, the managers are also faced by the practical issues which aim to improve the quality and efficiency of student management work.

\subsection{Multi-campus management makes the students work more difficult.}

Currently, most universities have sub-campuses, students managers sometimes have to run around between different campuses which lower down work efficiency, while, they can only do some simple transactional work which affects the continuity of work. Therefore, the establishment of College Student Scholarship can support all aspects of the work of student information management, educational management and decision making. It also upgrades the management level of student 
managers by promoting digital campus construction, standardization and information technology, and utilizing data integration and mining techniques for quick storing, searching, managing and analyzing.

\section{Awards appraised Algorithm application}

\subsection{Establish awards Index System.}

Scholarships aims to encourage students' learning progress, promote the student's development from all-round aspects of Moral, intellectual, physical, aesthetic and labor. Besides, scholarships assess overall performance of students within a school year (term), it not only confirm the students' self-development, but also further guide them to plan their future developing direction personally. Therefore, the correction and rationality of scholarship become a growing factor of individuals and society. This paper combined the expert invigoration method and fuzzy comprehensive evaluation method to construct a, more accurate, operational, and scientific scholarship evaluation system indicators.

After reviewing relevant literature and refining views by interviews with corporate human resources and university experts, the scholarship evaluation system is given in Figure1 which includes 3 first indicators and 11 secondary(Yang and Feng, 2015) indicators of practical Construction and academic development.

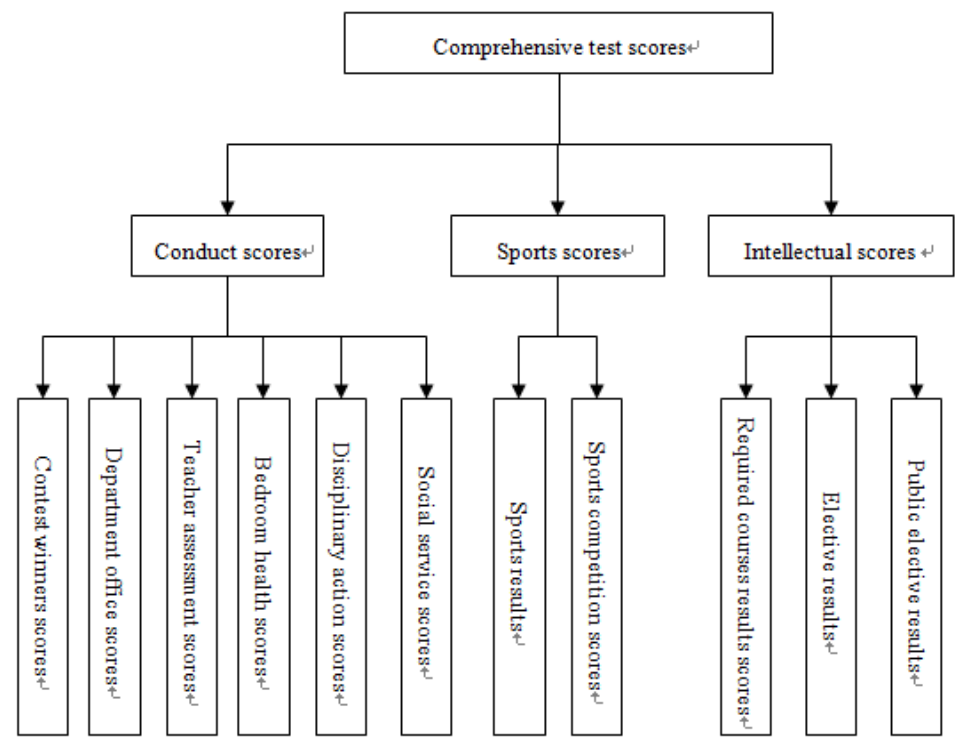

Fig. 1 Figure of scholarship evaluation index system

\subsection{It cannot start with Based on the Analytic Hierarchy Process (AHP) algorithm appraised awards.}

Fuzzy comprehensive evaluation, the main measure of the actual application and the actual data test set by the theoretical model of fuzzy mathematics, integrating the constraints and constraints, the thing vague qualitative evaluation into accurate quantitative assessment, upgrade evaluation efficiency. The method by fuzzy mathematical model depicts the underlying events and constraints on top of events, through the promotion of evaluation and calculation data, and ultimately affects the outcome of events underlying the calculation of the overall goal(Lu,2009)(Li and Zhang,2008). Fuzzy comprehensive evaluation (Zhang,2013)(Mohammad,2015) of the main process is to determine a degree of membership, which is to assess the membership degree of the object in the collection and evaluation of test conditions, that single factor fuzzy evaluation set $E_{i}=\left(e_{i 1}, e_{i 2}, e_{i 3}, \cdots, e_{i n}\right)$; then the weight vector A and mufti-factor fuzzy matrix multiplication obtained under fuzzy comprehensive evaluation set $\mathrm{B}$, that is, considering all factors in the case, the object of the evaluation judgment set membership degree $\mathrm{V}$ of each element. 


$$
B=A \cdot E=\left(a_{1}, a_{2}, \cdots a_{n}\right) *\left[\begin{array}{cccc}
e_{11} & e_{12} & \cdots & e_{1 m} \\
e_{21} & e_{22} & \cdots & e_{2 m} \\
\cdots & \cdots & \cdots & \cdots \\
e_{n 1} & e_{n 1} & \cdots & e_{n m}
\end{array}\right]=\left(b_{1}, b_{2}, \cdots b_{m}\right)
$$

Fuzzy comprehensive evaluation process is as follows: to identify factors set; Evaluation Index; Construction of single-factor evaluation and a collection of constraints; clearly measurable weight index. Evaluation results are accurate and clear, high system availability and reliability.

(1) Identify factors set

The scholarship evaluation system diagram can be obtained: the factor set $U$ consists of two indicators, namely, $U=\left(U_{1}, U_{2}\right) ; U_{1}=\left(b_{1}, b_{2}, b_{3}\right) ; U_{2}=\left(c_{1}, c_{2}, c_{3}, \cdots, c_{11}\right)$, obviously, where $b_{3}, c_{9}, c_{10}, c_{11}$ is academic, quantifiable calculation.

(2) Establishment of Evaluation Index

Indicators for evaluating indicators based systems require practical meaning and role, the papers will therefore scholarship evaluation of qualitative and quantitative indicators divided, table 1, 2 shown in the following:

Table 1. Evaluation of academic collections

\begin{tabular}{|c|c|c|c|c|}
\hline Grade & One & Two & Three & Four \\
\hline $\begin{array}{c}\text { Score (weighted } \\
\text { average) }\end{array}$ & $100-90$ & $89-80$ & $79-70$ & $69-60$ \\
\hline
\end{tabular}

Table 2. Evaluation of qualitative indicators set

\begin{tabular}{|c|c|c|c|c|}
\hline Grade & One & Two & Three & Four \\
\hline description & excellent & good & medium & passing \\
\hline
\end{tabular}

For quantitative indicators, it can be divided into four levels according to its corresponding value, namely intellectual achievement points, it can be a weighted average score is divided into four grades. In this way, fuzzy small absolute achievement gap, promoting as a measure of the main indicators of academic rigor, fairness.

For qualitative indicators, scoring by the class teacher, student cadres serving of bonus subjective assessment of ways to evaluate the students by realities of situation and practical appraisal indicators. On account of the lacking objective basis for comparison, narrative assessment index percentile or abandon the traditional scoring method is well prepared, in order to advance the accuracy of the assessment results, Likert-type scale to establish evaluation set.

(3) Single constraint Fuzzy Evaluation

Regarding the assessment collection as the basis, underlying index that is secondary indicators were single factor fuzzy evaluation, resulting in mufti-factor fuzzy evaluation set.

As qualitative indicators, summary of each evaluation results. Evaluation of the collection of indicators obtained membership based on qualitative indicators in Table $2 . \sum_{j=1}^{4} m_{i j}=1, m_{i j} \in[0,1]\left(m_{i j}\right.$ Represents the quantity of people involved in assessment $\mathrm{n}$, total $\mathrm{x}$ people give out the i-th secondary indicators evaluation as a j-level), there is $m_{i j}=x / n$.

(4) Index weight

Confirming index weight is one of the most important steps for fuzzy comprehensive evaluation, Fuzzy Analytic Hierarchy Process (Fuzzy-AHP) is applied in the paper to calculate the index weight.

According to a wizard named scholarship, the right to an index weights are set to: conduct points $=$ 0.3 , sports stars $=0.1$, intellectual 0.6 points, with expert investigation of the two indicators to be assessed. Figure 1 secondary indicators left to right to set membership: conduct $(0.2,0.2,0.2,0.1,0.2$, 
$0.1)$ Sports $(0.7,0.3)$ intellectual $(0.6,0.2,0.2)$. Which can get the two indicators of the weight of a combination of factors $(0.06,0.06,0.06,0.03,0.06,0.03)(0.07,0.03)(0.36,0.12,0.12)$.

(5) Comprehensive Evaluation

Order entry for the weight of $\mathrm{A}$, then $\mathrm{A}=(0.06,0.06,0.06,0.03,0.06,0.03,0.07,0.03,0.36,0.12$, 0.12 ) multifactor fuzzy matrix E, A row vector $1-9$, E is $11 \times 4$ matrix, after $A \cdot E$ vector with a $1 \times 4$. That is, too:

$$
E=\left[\begin{array}{cccc}
m_{11} & m_{12} & m_{13} & m_{14} \\
m_{21} & m_{22} & m_{23} & m_{24} \\
\cdots & \cdots & \cdots & \cdots \\
m_{111} & m_{112} & m_{113} & m_{114}
\end{array}\right] \quad \begin{aligned}
& \boldsymbol{B}=\boldsymbol{A} \cdot \boldsymbol{E}=\left(b_{1}, b_{2}, b_{3}, b_{4}\right) \\
& \quad \boldsymbol{R}=\left(r_{1}, r_{2}, r_{3}, r_{4}\right)
\end{aligned}
$$

(6) Sequence

Finally, the level parameter method calculated to reflect the value of participating rank overall quality of students, and the ranking values are sorted. According to the evaluation table set academic obtain the following formula:

Comprehensive points:

$$
\begin{aligned}
& S=B \cdot R^{T}=\sum_{i=1}^{4} b_{i} \cdot r_{i}, B=\left(b_{1}, b_{2}, b_{3}, b_{4}\right), R=(100,90,80,70), R^{T}=\left(\begin{array}{c}
100 \\
90 \\
80 \\
70
\end{array}\right) \\
& S=B \cdot R^{T}=\left(b_{1}, b_{2}, b_{3}, b_{4}\right) \cdot\left(\begin{array}{c}
100 \\
90 \\
80 \\
70
\end{array}\right)=100 \cdot b_{1}+90 \cdot b_{2}+80 \cdot b_{3}+70 \cdot b_{4}
\end{aligned}
$$

\section{Summary}

Reducing the workload of teachers and staff in the evaluation of student scholarships related work in the system to some extent. Students take advantage of human resources management, by means of information on all aspects of student learning, life, thought overall management. Helping college student's management work covers a wide range, tedious affairs, process diversity, time-sensitive stage, workload issues.

\section{References}

[1] Li L.H., Zhang Y., 2008, Application of a Fuzzy AHP Comprehensive Evaluation in Psychology, Northeast Normal University: Philosophy and Social Sciences, 3,169-174.

[2] Lu D.H., 2009, Fuzzy Comprehensive Evaluation Based on AHP in risk evaluation of highway geological disasters, Sichuan Geology, 29 (3), 357-340.

[3] Mohammad S.P., 2015, an integrated approach based on DEA and AHP, Computational Management Science, 1,153-169.

[4] Yang X.B., Feng S.Q., 2015, Research on the Middle-Distance Running Achievement Prediction for College Students Based on LSSVMGAS, Chemical Engineering Transactions,46, 409-414,DOI: 10.3303/CET1546069.

[5] Zhang Y.B., 2013, Application and Research of Fuzzy Analysis in Practice Teaching Evaluation, Information Systems Engineering, 11,149-151. 